\title{
LA LIMITACIÓN DE LOS DERECHOS EN LA LUCHA CONTRA LA COVID-19: ESPECIAL REFERENCIA A LA REFORMA DEL RECURSO DE CASACIÓN DE MAYO DE 2021
}

\author{
ANTONIO JESÚS ALONSO TIMÓN \\ Universidad Pontificia Comillas (ICADE)
}

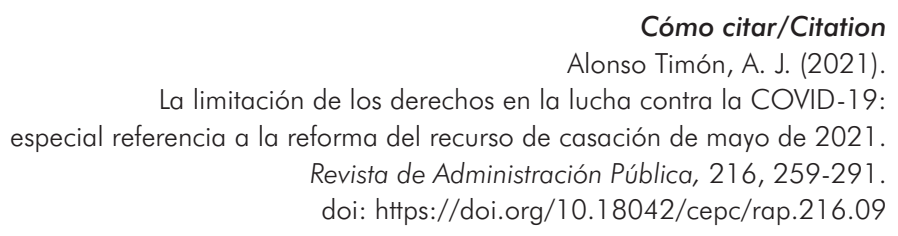

Resumen

El presente trabajo tiene como objetivo principal analizar la modificación del recurso de casación introducida en la Ley de la Jurisdicción Contencioso-Administrativa por el Real Decreto Ley 8/2021, de 4 de mayo. No parece que, ni desde el punto de vista formal ni desde el punto de vista material, esta sea la vía más ortodoxa para la consecución del objetivo de esta reforma, que no es otro que homogeneizar la jurisprudencia en torno a la autorización y ratificación de las medidas restrictivas de derechos adoptadas por las Administraciones públicas en la lucha contra la pandemia de la COVID-19. No obstante, gracias al sentido común de nuestro Tribunal Supremo, el objetivo se ha logrado y existe ya una jurisprudencia que fortalece la seguridad jurídica en la limitación de los derechos de los ciudadanos. Además, se abordan otras cuestiones relacionadas con la limitación de derechos en la pandemia, como el pasaporte COVID.

\section{Palabras clave}

Recurso de casación; restricciones de derechos por la COVID-19; jurisdicción contencioso-administrativa. 


\begin{abstract}
The main aim of this paper is to analyze the modification of the cassation appeal introduced in the Law of the Contentious-Administrative Jurisdiction by Royal Decree-Law 8/2021, of May 4. It does not seem that, neither from the formal point of view nor from the material point of view, this is the most orthodox way to achieve the objective of this reform, which is none other than homogenizing the jurisprudence around the authorization and ratification of the restrictive measures of rights adopted by the Public Administrations in the fight against the COVID-19 pandemic. However, the objective has been achieved, thanks to the common sense of our High Court and We have nowadays a clear jurisprudence in the limitation of the rights of the citizens. In addition, other questions related with the limitation of the rights, such as the COVID passport, are analyzed in the paper.
\end{abstract}

\title{
Keywords
}

Cassation Appeal; restrictions of rights by COVID-19; Contentious-Administrative Jurisdiction. 


\section{SUMARIO}

I. INTRODUCCIÓN. II. EL REAL DECRETO 8/2021, DE 4 DE MAYO. ANÁLISIS TÉCNICO DE LA REFORMA. III. LA OPCIÓN POR OTRA REFORMA PROCESAL PARA NO AFRONTAR LA NECESARIA REFORMA MATERIAL. ¿ेQUIEBRA DEL PRINCIPIO DE DIVISIÓN DE PODERES? IV. LOS OBJETIVOS DE LA REFORMA. HOMOGENEIDAD EN LA RESPUESTA JUDICIAL EN LA AUTORIZACIÓN Y RATIFICACIÓN DE MEDIDAS RESTRICTIVAS DE DERECHOS FUNDAMENTALES. V. ANÁLISIS DE LAS RESOLUCIONES JUDICIALES DICTADAS POR EL TRIBUNAL SUPREMO HASTA AHORA. VI. DISTINCIÓN ENTRE MEDIDAS RESTRICTIVAS: RESTRICCIÓN DE DERECHOS FUNDAMENTALES Y RESTO DE MEDIDAS RESTRICTIVAS. VII. EL CERTIFICADO COVID COMO MEDIDA LIMITATIVA DE LA MOVILIDAD SOCIAL. VIII. DE NUEVO EN LA LUCHA CONTRA LAS INMUNIDADES DEL PODER. IX. CONCLUSIONES.

\section{INTRODUCCIÓN}

El pasado 4 de mayo el Gobierno completó la reforma que había venido anunciando semanas antes de la finalización del segundo estado de alarma a nivel nacional, cuya duración ha sido de más de seis meses (seis meses y medio, concretamente), y que concluyó a las 00:00 horas del 9 de mayo de 2021.

Una vez adoptada la decisión de no prorrogar el mismo, con el fin de mitigar la posible disparidad de pronunciamientos por parte de los tribunales superiores de justicia en relación a las autorizaciones judiciales de las medidas restrictivas de derechos fundamentales que en la lucha contra la pandemia adoptasen a partir de ese momento las comunidades autónomas, el Gobierno optó por volver a modificar la Ley de la Jurisdicción Contencioso-Administrativa para atribuir al Tribunal Supremo la competencia, en casación, para la depuración de la jurisprudencia en relación a esta cuestión. Desde luego, no era este un territorio ignoto y el Gobierno lo sabía, ya que en el período que medió entre los dos estados de alarma de alcance nacional se habían producido pronunciamientos diferentes en los distintos tribunales superiores de justicia, por lo que ya estaba sobre aviso. 
Esta segunda reforma de la Ley de la Jurisdicción Contencioso-Administrativa en menos de un año en relación con la misma cuestión parece reconocer implícitamente que la llevada a cabo en el mes de septiembre de 2020 no dio los resultados esperados ${ }^{1}$ ¿ ¿Ocurrirá lo mismo ahora? A tenor de la sentencia dictada por el Tribunal Supremo el 3 de junio de 2021 y las reacciones que se han producido por parte de algunas comunidades autónomas en las que se mantenía una limitación a la movilidad de personas, más conocido erróneamente como "toque de queda», parece que algún beneficio podría derivarse de dicha reforma².

Sin embargo, el árbol no debe impedirnos ver el bosque. Cabe preguntarse si dicha reforma es el instrumento adecuado y más ortodoxo para otorgar seguridad jurídica a la situación generada por esta pandemia y si con ella el Gobierno ha pretendido seguir descargando el peso del coste político de la lucha contra la COVID-19, ya sea en las comunidades autónomas bajo la vigencia del estado de alarma, donde en el segundo de ellos reguló una especie de estado de alarma descentralizado, ya sea en los tribunales fuera de la vigencia del estado de alarma, obligando a que sean estos los que decidan, sin parámetros legales firmes, las medidas de limitación de derechos fundamentales que se pueden adoptar o no.

El debate acerca de si los tribunales pueden cumplir el papel que el Gobierno les ha otorgado se ha suscitado de manera clara. La sala de lo Contencioso-Administrativo del Tribunal Superior de Justicia de Aragón interpuso una cuestión de inconstitucionalidad contra el art. 10.8 de la Ley Jurisdiccional, en la redacción dada a dicho precepto por la reforma de septiembre de 2020, argumentando que, con dicha reforma, los tribunales deben decidir sobre la conformidad de estas medidas tras el oportuno procedimiento, estudiando a fondo el expediente y los motivos y pretensiones de los ciudadanos que lo recurren y razonan, y que lo contrario sería colocar a los tribunales en una posición de Administración colaboradora, con la dificultad que ello supone si con posterioridad se produce un recurso, el cual se presentaría ante el tribunal enfrentándose a una decisión ya confirmada por este, lo que da una falsa impresión de conformidad a la legalidad. En definitiva, se cuestiona implícitamente si lo que verdaderamente está ocurriendo es que no se está respetando el principio de división de poderes y si realmente lo que se está atribuyendo a los tribunales

1 Nos referimos a la reforma llevada a cabo por la disposición final segunda de la Ley 3/2020, de 18 de septiembre, de medidas procesales y organizativas para hacer frente a la COVID-19 en el ámbito de la Administración de Justicia $(B O E, 19$ de septiembre de 2020).

2 Esta sentencia de 3 de junio de 2021 resuelve el recurso de casación interpuesto por el Ministerio Fiscal contra el auto de 20 de mayo de 2021 del TSJ de las islas Baleares que ratificó las medidas adoptadas por el gobierno de dicha comunidad para combatir la pandemia de la COVID-19 tras el cese del segundo estado de alarma. 
no debería haber sido previamente rodeado de una mayor zona de certidumbre jurídica mediante la intervención del poder encargado de ello, como es el poder legislativo, mediante las oportunas reformas legales que sirviesen de vehículo para una mejor adaptación de las medidas a adoptar en la lucha contra esta pandemia.

Este debate no es nuevo. Surgió también el año pasado en los inicios de la pandemia y el Gobierno, en principio, parecía dispuesto a llevar a cabo las reformas necesarias en la legislación sanitaria para mejorar la seguridad jurídica en la lucha contra la misma. Sin embargo, finalmente no se ha considerado oportuno seguir ese camino, lo que ha complicado sobre manera la posición en la que se encuentran unos tribunales que tienen que acudir a principios generales del derecho en sus resoluciones sobre esta materia ante la ausencia de preceptos legales que regulen con precisión esta cuestión y sirvan de apoyo jurídico tanto a los diferentes poderes ejecutivos territoriales como a los diferentes tribunales con competencias para la autorización o ratificación de medidas restrictivas de derechos fundamentales y no fundamentales.

La reforma operada en el recurso de casación en mayo de 2021 es otra muestra más de la falta de interés que el Gobierno de la nación ha mostrado de manera reiterada a la hora de dotar a todos los llamados a aplicar las normas de instrumentos que favorezcan la seguridad jurídica y respeten los derechos constitucionalmente reconocidos.

\section{EL REAL DECRETO 8/2021, DE 4 DE MAYO. ANÁLISIS TÉCNICO DE LA REFORMA}

Dos son, a mi juicio, las cuestiones que sobre la reforma del recurso de casación llevada a cabo a través del citado Real Decreto Ley 8/2021 merecen ser analizadas. Una de forma y otra de fondo. Respecto de la cuestión formal, debemos llamar la atención, de nuevo, sobre el abuso que del real decreto ley se está haciendo, no ya durante la pandemia, donde se ha agravado, sino en los últimos ańos ${ }^{3}$. En relación con la cuestión de fondo, cabe preguntarse si el Tribunal Supremo es el órgano adecuado para conocer en casación sobre normativa autonómica ${ }^{4}$.

3 En este sentido, véase E. Arana García (2013): «Uso y abuso del decreto-ley», Revista de Administración Pública, 191, págs. 337-365.

4 Sobre las dudas acerca de la competencia del Tribunal Supremo para conocer de estos asuntos en los términos aquí planteados, véase, por ejemplo, J. A. Santamaría Pastor (2017) (coord.), «1700 preguntas sobre contencioso-administrativo», Madrid: Francis Lefebvre. O, más recientemente, O. Bouazza Ariño (2021), La casación en el contencioso-administrativo, Pamplona: Civitas. 
El recurso continuado al real decreto ley ha supuesto la puntilla a la ya de por sí maltrecha técnica normativa en España en los últimos años ${ }^{5}$. Es, sin duda, una cuestión que debería preocuparnos y hacernos reflexionar. Aunque no es el objeto principal de este trabajo, sí que debemos poner de manifiesto que tal hecho conduce a un empequeñecimiento del papel del poder legislativo en nuestro sistema democrático, habiendo quedado este, de manera clara e indubitada, a merced del poder ejecutivo, lo cual no habla muy bien de la calidad de nuestro sistema democrático. El peligro que un abuso reiterado, irresponsable y muy consciente como el que ahora denunciamos conlleva se ha visto de manera cristalina durante la lucha contra la pandemia de la COVID-19, donde el poder ejecutivo ha ninguneado de manera cuasi inconstitucional al legislativo ${ }^{6}$, quien ante una crisis tan grave como esta, no ha ejercido su función principal, que no es otra que la de representar la soberanía nacional y aprobar todas aquellas normas limitativas de derechos con la legitimidad que la representación popular le ha otorgado $^{7}$. En el año 2020 se publicaron en España 39 reales decretos leyes, lo que supone un incremento de un $220 \%$ sobre el año 2019. Este dato refleja muy bien la mano de hierro con la que el poder ejecutivo ha gestionado la pandemia y el papel absolutamente residual que el Parlamento de la nación ha tenido. Pero el problema no es solo cuantitativo. Es peor, incluso. El problema es también cualitativo. No es ya que se aprueben muchos reales decretos leyes. Es que los que se aprueban adolecen de importantes lagunas o defectos.

Se sustituye el «sosiego» del trámite parlamentario, que garantiza la reflexión, el debate público, el contraste de ideas y, consecuentemente, la pluralidad democrática y el perfeccionamiento de la norma, por el «trasiego» y las prisas por aprobar, de cualquier manera y sobre cualquier materia, sin debate, sin reflexión y sin pericia, normas de dudosa factura jurídica?.

5 En el siguiente link se pueden consultar unos interesantes cuadros que nos detallan la evolución de la producción normativa en nuestro país, destacando el repliegue sufrido por la ley frente al real decreto ley desde el año 2015. https://bit.ly/3aTkeGK.

6 Así lo ha corroborado la reciente sentencia del Tribunal Constitucional de 5 de octubre de 2021, no publicada en la fecha de cierre de este trabajo, pero cuyo resumen y razonamiento principal se puede consultar en la nota de prensa emitida por el gabinete de comunicación del Tribunal Constitucional el mismo día 5 de octubre de 2021 (nota 87/2021).

7 El abuso al recurso «excepcional» del real decreto ley se ha acentuado en los últimos tres años. Este hecho no ha pasado inadvertido en los medios de comunicación, quienes han informado con datos sobre el particular. Véase, por ejemplo, la noticia publicada ya el año pasado por elconfidencial.com en el siguiente link: https://bit.ly/3FZVQRQ.

8 Véase el informe de producción normativa elaborado por la CEOE y publicado en febrero de 2021: «La producción normativa en 2020». Se puede consultar en el siguiente link: https://bit.ly/3BXdSSw.

9 Sobre algunos de los defectos graves observados en el manejo frenético de los reales decretos leyes, véase M. M. Fernando Pablo (2021), «Sobre la creación, categoriza- 
El Real Decreto Ley 8 /2021, de 4 de mayo, no es una excepción. La lectura de su título o rótulo ya nos da una idea de que el poder ejecutivo, acuciado por la finalización del segundo estado de alarma nacional, ha ido contrarreloj en la tramitación y aprobación de dicha norma. Los 15 artículos que lo integran confirman las sospechas. Se trata de otro intento por paliar, en algunos aspectos, los efectos perniciosos de la inacción gubernamental durante más de un año para adaptar la legislación sanitaria a la situación generada por esta pandemia. Uno de esos aspectos, por ejemplo, es la negativa a modificar el art. 3 de la Ley Orgánica 3/1986, de 14 de abril, de medidas especiales en materia de salud pública, cuestión que está directamente relacionada con la reforma del recurso de casación que lleva a cabo el artículo 15 de este real decreto ley. La reforma de dicho artículo le ha sido sugerida al Gobierno en numerosas ocasiones y por distintos colectivos (doctrina, oposición y hasta, de manera cada vez más velada, por la propia jurisprudencia) ${ }^{10}$. La inminencia de la finalización del estado de alarma el 9 de mayo de 2021 hizo que el Gobierno tuviese, de nuevo, que improvisar una nueva norma técnicamente imperfecta, como veremos, para encontrar un anclaje jurídico que respaldase, o no, las medidas limitativas de derechos fundamentales que las Administraciones públicas territoriales, especialmente las comunidades autónomas, que son en quien el Gobierno de la nación ha decidido descargar la

ción y aplicación de la nueva legalidad: alarma en el estado de Derecho», Revista de Administración Pública, 214, págs. 253-280. La gravedad de esta situación llega al extremo, como pone de manifiesto el autor de este trabajo en la página 258, de haber convalidado algún real decreto ley en el Congreso fuera del plazo de un mes otorgado por el art. 86.2 de la Constitución.

10 El Partido Popular llegó a presentar en el mes de agosto de 2020 en el Congreso de los Diputados la Proposición de Ley Orgánica 122/000077. La modificación propuesta del art. 3 de la Ley Orgánica 3/1986 era la siguiente (artículo 2 de la proposición de ley): «Se modifica el artículo tercero de la Ley 3/1986, de 14 de abril, que quedará redactado de la siguiente forma: Artículo tercero.

1. Con el fin de controlar las enfermedades transmisibles, la autoridad sanitaria podrá:

a) Realizar las acciones preventivas generales.

b) Adoptar las medidas oportunas para el control de los enfermos, de las personas que estén o hayan estado en contacto con los mismos y del medio ambiente inmediato. Dichas medidas incluirán el sometimiento obligado de las personas sospechosas a observación de salud pública; sometimiento a cuarentena o aplicar otras medidas sanitarias para las personas sospechosas; sometimiento a aislamiento y a tratamiento, cuando proceda, a las personas afectadas, así como la localización de quienes hayan estado en contacto con personas sospechosas o afectadas.

c) Controlar o limitar las entradas y salidas de la zona afectada o amenazada y controlar o limitar el movimiento dentro de dicha zona, lo cual podrá afectar al derecho a la libre circulación y deambulación por vías públicas, así como a derecho de reunión que podrá estar condicionado en su ejercicio tanto en lugares determinados como en el número de personas.

d) Las que se consideren necesarias en caso de riesgo de carácter transmisible.

2. Todas las medidas se tomarán conforme a los principios de necesidad, idoneidad y proporcionalidad». 
responsabilidad principal de la lucha contra la pandemia, adopten fuera del paraguas de dicho estado de alarma.

Desde luego, no parece que un real decreto ley, en general, sea el instrumento jurídico más ortodoxo para dar una solución jurídica adecuada y completa a una cuestión tan trascendente y compleja y, en especial, no parece que este Real Decreto Ley 8/2021 sea el cauce apropiado para que, en medio de tanta miscelánea, se pueda abordar con la seriedad y el sosiego exigible y exigido la respuesta jurídica que las Administraciones públicas territoriales deben dar a una pandemia que se ha llevado por delante a más de 100.000 españoles. El Gobierno ha elegido desde hace tiempo el camino jurídico más incierto y revirado. Y está cosechando los resultados esperados en forma de varapalos judiciales y toques de atención continuos por parte de diferentes operadores jurídicos.

Y no será porque no haya habido tiempo para reflexionar. Y no será porque no haya habido tiempo para rectificar. Se puede alegar que la extraordinaria y urgente necesidad que el art. 86.1 exige para regular mediante real decreto ley una materia está presente en el caso de esta pandemia. Y ciertamente es así. No se puede negar que, en los momentos iniciales, allá por el mes de marzo de 2020, se cumplían esos requisitos: la urgencia y la necesidad. Sin embargo, no parece que ese argumento se pueda mantener en el tiempo, una vez que han transcurrido ya más de quince meses en los que habría dado tiempo a elaborar una respuesta normativa más consensuada, sosegada y democrática, a través de una mayor participación del poder legislativo, como ya se ha explicado más arriba. Por consiguiente, aprobar un real decreto ley de estas características, generalista y misceláneo como el que se ha aprobado, supone en la práctica, incluso, un retroceso respecto a la reforma que de la Ley Jurisdiccional se llevó a cabo en septiembre de 2020 desde el punto de vista de la ortodoxia normativa. Al menos, aquella reforma se llevó a cabo dando alguna oportunidad al debate parlamentario y sin tantas prisas ni improvisación.

Desde el punto de vista formal, debemos seguir insistiendo en que la opción elegida por el Ejecutivo para llevar a cabo esta reforma del recurso de casación no es la más adecuada.

Supone un nuevo desprecio al poder legislativo y refleja, de manera tangible, la improvisación con la que la gestión de esta pandemia ha sido llevada por parte del poder ejecutivo, tal y como de manera indisimulada se afirma en la exposición de motivos de la norma. Y lo que es peor: presenta serias dudas de constitucionalidad al afectar de manera directa al ejercicio de derechos fundamentales, como el gabinete técnico del propio Tribunal Supremo se ha encargado de señalar.

Entrando ya en el aspecto material de la reforma del recurso de casación operado por el citado Real Decreto Ley 8/2021, son varios los aspectos técnicos sobre los que me gustaría llamar la atención. El primero es si esta reforma respeta el principio hasta ahora mantenido de que el Tribunal Supremo no es el órgano competente para analizar en vía casacional la normativa de las comunidades autónomas. El segundo es si la misma no supone un reconocimiento implícito del 
fracaso de la reforma llevada a cabo en septiembre de 2020 y si, verdaderamente, va a conseguir los objetivos de unificación de la doctrina jurisprudencial que persigue, pues no es descartable que, en algunos supuestos, el Tribunal Supremo ni siquiera pueda llegar a pronunciarse sobre el fondo del asunto por diversos motivos, como, por ejemplo, que no exista un verdadero interés casacional. En definitiva, en último término, esta reforma podría suponer un paso atrás en la regulación del certiorari introducido en nuestra legislación procesal contencioso-administrativa por la reforma de 2015 que entró en vigor en 2016.

Me voy a centrar ahora, primordialmente, en el primero de ellos, puesto que la segunda cuestión planteada será analizada con mayor detalle en otro apartado de este trabajo.

El art. 87.1.bis de la Ley de la Jurisdicción Contencioso-Administrativa afirma que serán susceptibles de recurso de casación, en todo caso, los autos dictados en aplicación del art. 10.8 y del art. 11.1.i) de dicha ley ${ }^{11}$. El problema que se plantea respecto de dichos autos es que se refieren a autorizaciones y ratificaciones de medidas sanitarias contra la COVID-19 adoptadas por las comunidades autónomas y no siempre en cumplimiento de normativa estatal. Es decir, no siempre por imposición directa o cumplimiento «obligatorio» de esa extraña avis jurídica de nuevo cuńo denominada «orden comunicada», sino por la voluntad libérrima de cada comunidad autónoma que, en función de la situación epidemiológica que tiene en cada momento, adopta decisiones propias que afectan de manera muy directa a los derechos fundamentales de las personas físicas de sus respectivos territorios o a otros derechos igualmente importantes, como es el derecho a la libertad de empresa, que también es esencial para las personas jurídicas que ejercen su actividad en ese espacio territorial. En definitiva, es perfectamente factible, como la práctica nos ha demostrado ${ }^{12}$, que el Tribunal Supremo se encuentre, por esta vía de recurso de casación, enjuiciando una normativa estrictamente autonómica que no se ha dictado en desarrollo ni en cumplimiento de ninguna normativa estatal, lo que plantea una duda competencial de primer orden acerca de si el Tribunal Supremo es el órgano competente para conocer de estas cuestiones, ya que el art. 86.3 de la Ley Jurisdiccional es muy claro por lo que a las sentencias de los Tribunales Superiores de Justicia hace referencia. Y si dicho precepto es así de claro respecto de resoluciones judiciales que, con carácter general, dilucidan asuntos que tienen un mayor interés casacional, ¿cómo se puede justificar técnicamente que

11 Este art. 87.1.bis ha sido introducido en la Ley Jurisdiccional por el art. 15 del Real Decreto Ley 8/2021, de 4 de mayo.

12 Véase, por ejemplo, la sentencia del Tribunal Supremo de 3 de junio de 2021 (Sentencia $788 / 2021$, número de procedimiento $3704 / 2021$ ), que analizaremos en este trabajo, por la que se resuelve el recurso de casación interpuesto por el Ministerio Fiscal contra el auto de 20 de mayo del TSJ de las Islas Baleares por el que se ratificaban las medidas de restricción sanitarias adoptadas por acuerdo del Consejo de Gobierno de dicha comunidad el 17 de mayo de 2021. 
el Tribunal Supremo tenga que pronunciarse, en todo caso, como indica literalmente el nuevo art. 87.1.bis, sobre cuestiones que, en principio, tienen menor interés casacional y en las que se ventila normativa autonómica? En la práctica, se ha creado un recurso de casación estatal para autos «de normativa autonómica» que supone una quiebra técnica en la regulación de dicho recurso, que no reconoce esta posibilidad ni para las sentencias que han interpretado normativa autonómica ni para el resto de autos en los que se ventile dicha normativa. No parece coherente tal opción ni congruente con la construcción jurídica que del recurso de casación en materia contencioso-administrativa se ha llevado a cabo desde que se introdujese por primera vez en dicho orden jurisdiccional en 1992.

Asimismo, otro de los problemas que plantea esta reforma y que fue puesto de manifiesto por el gabinete técnico del Tribunal Supremo, es que al suprimirse el filtro inicial que hay para los recursos de casación, es posible que el Tribunal Supremo no llegase a pronunciarse sobre el fondo del asunto que le llegase, rechazando la impugnación por problemas formales o falta de interés casacional. La falta de interés casacional en los términos en los que dicho interés casacional se reguló en 2015 es obvia hasta para el propio Ejecutivo impulsor de esta reforma a través del Ministerio de Justicia, que ha renunciado a modificar el art. 88. La falta de filtros a la que alude en su primera nota informativa el citado gabinete técnico se refleja en la regulación que del procedimiento de admisión de este recurso se contiene ahora en el art. 87ter, que suprime el trámite de preparación del recurso ante el tribunal a quo y establece un plazo sumario por el que el Tribunal Supremo deberá resolver en ocho días, sumados los tres de traslado a las partes para que aleguen y los cinco posteriores para que el Tribunal Supremo dictamine. La necesidad de examinar con un mínimo de detalle la controversia y la complejidad de que en un plazo tan exiguo se pueda estudiar con rigor estos asuntos dificulta no solo el cumplimiento estricto de estos plazos, como también se ha criticado desde el propio Tribunal Supremo, sino que plantea el problema de la constitucionalidad de la posición institucional en que se viene a situar a los tribunales de justicia, como una suerte de copartícipes ejecutivos en el proceso de adopción de medidas administrativas, al modo de las competencias administrativas compartidas ${ }^{13}$.

Desde luego, la reforma operada en el recurso de casación por el Real Decreto Ley 8/2021, de 4 de mayo, presenta, desde mi punto de vista, deficiencias técnicas que ya se advertían desde el mismo momento en que fue aprobado. Sin embargo, afortunadamente, como veremos también, la sensatez y pragma-

13 Esta polémica, como ya se ha comentado, la ha planteado abiertamente en la «fase anterior» de reforma de la LJCA de septiembre de 2020, el TSJ de Aragón, que planteó ante el Tribunal Constitucional una cuestión de inconstitucionalidad mediante auto de 3 de diciembre de 2020, que fue admitida a trámite por providencia del Pleno del Tribunal Constitucional de 18 de febrero de 2021. 
tismo con que la Sala Tercera ha gestionado esta reforma ha conseguido evitar algunos de los males que inicialmente podían atisbarse.

\section{LA OPCIÓN POR OTRA REFORMA PROCESAL PARA NO AFRONTAR LA NECESARIA REFORMA MATERIAL. ¿ QUIEBRA DEL PRINCIPIO DE DIVISIÓN DE PODERES?}

La opción elegida por el Gobierno a comienzos de mayo de 2021 supone, de nuevo, no abordar la reforma material de nuestra legislación para adaptar la gestión pública a esta pandemia. A pesar de que tanto la oposición como la doctrina e, incluso, la propia jurisprudencia demanda otras alternativas, el Ejecutivo, que inicialmente en el mes de mayo de 2020, cuando estaba cercano el final del primer estado de alarma de ámbito nacional, expresó su intención de acometer estas reformas, cambió de opinión y optó por no tocar prácticamente nada de la legislación sectorial sanitaria ${ }^{14}$.

La apuesta por reformar la legislación procesal contencioso-administrativa, tanto en septiembre de 2020 como en mayo de 2021, ha sido cuestionada por la propia jurisprudencia, alegando que dichas reformas sitúan al poder judicial en una difícil posición, por cuanto le convierte en una especie de colaborador necesario y, por tanto, cómplice de la Administración pública, que renuncia expresamente a su privilegio de autotutela en la toma de decisiones sanitarias que restringen derechos fundamentales ${ }^{15}$.

14 Sobre esta cuestión, véase, A. J. Alonso Timón (2021), «La revisión judicial de las medidas limitativas de derechos en el marco del COVID-19», en A. J. Alonso Timón (coord.), Visión critica de la gestión del COVID-19 por la Administración (págs. 91-112), Madrid: Francis Lefebvre.

15 El TSJ de Aragón ha llegado a afirmar en el fundamento jurídico quinto de su auto de 3 de diciembre de 2020 (rec. 332/2020) que: «[...] el artículo 10.8 supone la renuncia por la Administración al privilegio de autotutela declarativa —artículo 103 de la CE-situando en el Poder Judicial, en las Salas de lo Contencioso-Administrativo, el deber de definir el derecho en el caso concreto, como ocurre en el resto de las jurisdicciones, pero, a diferencia de lo que ocurren en las demás, sin posibilidad de fundar la decisión judicial en un juicio de contradicción. Son las Salas de lo Contencioso-Administrativo — Poder Judicial — las que asumen la responsabilidad de una decisión general y política que responde a criterios y motivaciones diferentes a las propias de una decisión netamente judicial, asumiendo, como decíamos al principio, una función consultiva vinculante que la Constitución no le confiere». Y dice más en ese mismo fundamento jurídico quinto, afirmando que: «Por eso, no es que dudemos ahora de la constitucionalidad de una norma que despoja a la Administración del privilegio de autotutela cuando requiere para su validez de la autorización o ratificación judicial en el caso del artículo 10.8, sino que de lo que dudamos es de que, pese a la loable y bienintencionada voluntad que habrá guiado al Legislador, de lo cual la Sala no duda, esto sea ajustado a la Constitución, cuando, correlativamente, no hay fundamen- 
Creemos que esta reforma supone otra renuncia del Gobierno a tomar decisiones incómodas, traspasando esa responsabilidad, en última instancia, a los tribunales y sembrando la duda acerca de su constitucionalidad por atribuir al poder judicial facultades no conferidas al mismo por la propia Constitución, ya que los tribunales tienen atribuida la facultad de controlar la legalidad de la actuación administrativa cuando esta ya se ha producido y despliega efectos, es decir, ya es eficaz. Pero si la actuación administrativa no es eficaz mientras no la autorice o ratifique un tribunal, entonces no hablamos de actuación administrativa, sino de propuesta de actuación, o de actuación con eficacia diferida, que estaría a la espera del visto bueno de los jueces. Y esto es precisamente lo que ocurre en el caso de los arts. 10.8 y 11.1 i) reformados en septiembre de $2020^{16}$.

Pareciera como si al Gobierno le quemase la pandemia. Tras el fiasco inicial, con la asunción de competencias centralizadas en cuatro departamentos ministeriales durante el primer estado de alarma de ámbito nacional, ha ido soltando lastre. A favor de las comunidades autónomas, a las que se les impone la adopción de medidas restrictivas de derechos a los ciudadanos de sus respectivos ámbitos territoriales no sin antes hacerles pasar por la horca caudina del Consejo Interterritorial del Sistema Nacional de Salud y obligarles a ejecutar lo allí acordado a través de ese diabólico y discutible instrumento jurídico que son las «órdenes comunicadas». Y a favor de la jurisdicción contencioso-administrativa, a cuyos órganos colegiados se les obliga a pronunciarse en un plazo de tiempo exiguo sobre la adopción de medidas supuestamente técnicas que tienen a veces un sesgo político indudable, como se ha visto, y que necesitan, así, de la concurrencia de la voluntad de dicho orden jurisdiccional para que desplieguen efectos, en una especie de procedimiento administrativo bifásico que, desde luego, no se ajusta al esquema de división de poderes diseñado por nuestra Constitución.

La alternativa más razonable y respetuosa con el principio de legalidad y con la división de poderes hubiera sido, a mi juicio, la adaptación de la legislación

to constitucional para que las Salas de lo Contencioso-Administrativo ejerzan una función consultiva vinculante, prejudicial, participando de este modo del proceso de elaboración de un acto administrativo - o de una disposición general - que contiene medidas del tipo de las enunciadas en el precepto cuestionado. No parece, al menos esta Sala no lo considera así, que sea posible hallar ese fundamento en el artículo 117.3 de la CE, ni que la función de garantía de un derecho fundamental —artículo 117.4 de la CE—, cuyo titular es siempre el ciudadano individual, permita rebasar el límite de lo judicial, del ejercicio de la función jurisdiccional tal y como debe ser entendida en la Jurisdicción Contencioso Administrativa». Estos argumentos son los que llevaron a este mismo tribunal a interponer la ya citada cuestión de inconstitucionalidad que todavía no ha sido resuelta.

16 Sobre el papel desempeñado por la justicia administrativa en el control de las actuaciones administrativas durante el primer estado de alarma, especialmente los dos primeros meses, véase J. R. Fernández Torres (2020), «La Justicia Administrativa durante el estado de alarma», en D. Blanquer Criado (coord.), COVID-19 y Derecho Público (durante el estado de alarma y más allá) (págs. 325 a 398). Valencia: Tirant lo Blanch. 
material sanitaria a las necesidades de gestión que se han venido presentando a lo largo de estos últimos meses. La opción elegida, como se viene comentando, siembra dudas de constitucionalidad.

\section{LOS OBJETIVOS DE LA REFORMA. HOMOGENEIDAD EN LA RESPUESTA JUDICIAL EN LA AUTORIZACIÓN Y RATIFICACIÓN DE MEDIDAS RESTRICTIVAS DE DERECHOS FUNDAMENTALES. ALGUNOS POTENCIALES PROBLEMAS TÉCNICOS MITIGADOS, AFORTUNADAMENTE, POR LA REALIDAD FÁCTICA}

El objetivo que el legislador persigue con la reforma del recurso de casación de mayo de 2021 es homogeneizar la respuesta judicial en la autorización y ratificación de las medidas restrictivas de derechos adoptadas por las Administraciones públicas territoriales en la lucha contra la COVID-19. De hecho, desde mi punto de vista, esta reforma supone reconocer implícitamente el fracaso de la llevada a cabo en septiembre de 2020, cuando se decidió «ascender» la competencia para conocer de este tipo de decisiones, detrayéndola de los juzgados provinciales a los tribunales superiores de justicia (en el caso de la autorización y ratificación de las medidas adoptadas por las comunidades autónomas) y a la Audiencia Nacional (para las medidas adoptadas por la Administración General del Estado).

Ya hemos analizado en el apartado anterior los problemas que desde el punto de vista de la separación de poderes implican estas dos reformas, tanto la de septiembre de 2020 como la de mayo de 2021. Pero es que, adicionalmente, esta reforma del recurso de casación llevada a cabo para que el Tribunal Supremo ponga fin a la disparidad de criterios que, incluso con la reforma de septiembre de 2020, se ha producido entre los tribunales superiores de justicia, presenta también algún que otro defecto técnico que ahora analizaremos.

Con la finalización del segundo estado de alarma de ámbito nacional, el Gobierno estaba preocupado por la diferente interpretación que los tribunales superiores de justicia podían llevar a cabo acerca de las medidas restrictivas de derechos fundamentales que las diferentes comunidades autónomas pudieran adoptar fuera del paraguas de ese estado de alarma. En el período de tiempo entre los dos estados de alarma de ámbito nacional, el que va de primeros de junio a mediados de octubre de 2020, ya se habían dictado pronunciamientos divergentes por parte de dichos órganos jurisdiccionales ${ }^{17}$. Incluso, días antes de que el Gobierno optase por la reforma del recurso de casación debido al final del estado

17 La necesidad de "unificar doctrina» fue una de las razones que la vicepresidenta primera del Gobierno, Carmen Calvo, esgrimió en la rueda de prensa posterior al Consejo de Ministros donde se aprobó esta reforma para justificar su necesidad, con el fin de evitar la situación que se dio tras el primer estado de alarma, con dictámenes judiciales contradictorios sobre las medidas restrictivas, según indicó la citada vicepresidenta. 
de alarma, una encuesta llevada a cabo por una editorial jurídica no auguraba la tan ansiada homogeneidad de respuesta judicial con la que el Gobierno pretendía gestionar la lucha contra la pandemia sin estado de alarma ${ }^{18}$. Así, si todavía albergaba alguna duda, decidió, finalmente, acelerar la decisión de atribuir al Tribunal Supremo la competencia para pronunciarse con carácter definitivo acerca de las medidas restrictivas de derechos adoptadas, fundamentalmente, por las comunidades autónomas.

Sin embargo, como se apuntaba más arriba, esta reforma operada por el Gobierno presenta algunas deficiencias técnicas. En primer lugar, como indica el informe del gabinete técnico del Tribunal Supremo, dado que se prescinde del trámite previo para determinar si concurren los requisitos legales para admitir el recurso, puede que la propia Sala de lo Contencioso-Administrativo del Tribunal Supremo sea la que, en su resolución, establezca que debe inadmitirse el recurso porque no hay interés casacional (por ejemplo, por ser una cuestión puramente casuística) y no estudie ni se pronuncie sobre el fondo del asunto. A este respecto, el gabinete técnico del Tribunal Supremo lamenta que se suprima la fase de preparación del recurso de casación ante el Tribunal Superior de Justicia o ante la Audiencia Nacional, permitiendo que se presente directamente ante el Supremo, lo que plantea numerosos interrogantes y problemas prácticos referidos sobre todo a la imposibilidad de filtrar esos requisitos legales y el propio interés casacional. Por ello, esta reforma supone, de facto, una quiebra del carácter profiláctico que el recurso de casación tiene. Recordemos que no se modifica el art. 88 de la Ley Jurisdiccional ni, por ende, se incluye ningún atisbo de certiorari. En este sentido, es necesario recordar que en un reciente Auto de 24 de marzo de 2021 el Alto Tribunal explicó de forma ampliamente argumentada que contra las decisiones de los tribunales superiores de justicia y de la Audiencia Nacional

18 Durante el mes de abril de 2021 la editorial SEPIN realizó una encuesta jurídica en su boletín de Derecho Administrativo online en la que participaron varios magistrados de lo Contencioso Administrativo adscritos a diferentes tribunales superiores de justicia con el siguiente título: «Tras el levantamiento del estado de alarma, ¿pueden las Comunidades Autónomas, fuera del estado de alarma, adoptar medidas restrictivas de derechos fundamentales?; en caso afirmativo, ¿qué medidas pueden adoptar? ¿Cuál es su extensión y límites, cuál es el ámbito del control judicial de tales medidas?». Ninguna de las respuestas fue unánime y todas ellas interpretaban de manera diferente las posibilidades que las comunidades autónomas tenían para adoptar medidas restrictivas sin el amparo del estado de alarma, lo que hacía presagiar que volveríamos al caos jurisprudencial vivido tras la finalización del primer estado de alarma a nivel nacional, por lo que esto, junto con otros motivos reforzó la decisión del gobierno de apostar por la reforma del recurso de casación para que esta materia fuera objeto del mismo y que el Tribunal Supremo pusiera orden en dicho caos. 
que rechazaban o autorizaban las medidas sanitarias adoptadas por las diferentes Administraciones públicas territoriales no cabía recurso de casación ${ }^{19}$.

No obstante, tras la reforma, por cuestiones de pragmatismo procesal y material, el Tribunal Supremo se ha visto obligado a cambiar su parecer y aceptar el interés casacional de estos asuntos. Y ciertamente la tienen por la relevancia de lo que en ellos se está dilucidando (nada más y nada menos que restricciones de derechos fundamentales que afectan a un gran colectivo de personas), pero se ha articulado mal en la forma.

En otro orden de cosas, se llegaron a expresar dudas por parte de algunas instancias judiciales sobre la posibilidad real de poder cumplir con los plazos establecidos por el real decreto ley de reforma del recurso de casación de mayo de 2021, que son más cortos que los habituales, debiendo resolver el Supremo en unos ocho días, sumados los tres de traslado a las partes para que aleguen y los cinco posteriores para que el TS dictamine. En el referido informe que de manera rápida tras la reforma emitió el gabinete técnico del Tribunal Supremo se indicó sobre este particular literalmente lo siguiente:

[...] si, como es de temer, se multiplica la litigiosidad en esta materia, resultará muy problemático resolver los recursos en tan breve plazo, habida cuenta que al Tribunal Supremo accederán, probablemente en fechas coincidentes, recursos procedentes de cualesquiera tribunales inferiores». Por dicho motivo, el gabinete técnico recomendaba reforzar sus medios personales y materiales, muy saturados de trabajo ya, y crear una nueva sección dedicada solo a estos recursos.

Afortunadamente, esta acumulación de trabajo en el Tribunal Supremo no se ha producido porque el primer pronunciamiento sobre la materia mediante sentencia de 3 de junio de $2021^{20}$ fue muy claro. De hecho, las comunidades autónomas han ido adaptando sus medidas a dicho pronunciamiento, sobre todo las Islas Baleares y la Comunidad Valencia, que eran las que habían tratado de imponer una limitación general a sus ciudadanos del derecho a la libertad de circulación de personas o del derecho de reunión, manteniendo un toque de queda generalizado que, según el citado pronunciamiento del Tribunal Supremo, no tenía base jurídica. Al menos, desde ese punto de vista, se ha conseguido par-

19 En dicho auto, el Tribunal Supremo indica como argumento principal para defender la imposibilidad de recurso de casación en este tipo de procedimientos que no reviste naturaleza contradictoria, que en él no debaten las partes procesales enfrentadas, sino que opera como un procedimiento de cognición limitada, preferente y sumario, incardinado en el ámbito de la protección jurisdiccional de los derechos fundamentales, que tiene por objeto la autorización o ratificación judicial de medidas limitativas de derechos fundamentales, adoptadas por razones de salud pública. No se trata, insiste, de un procedimiento contradictorio, pues en el mismo solo interviene la Administración pública que acuerda tales medidas.

20 Sentencia 788/2021. 
cialmente el objetivo de la reforma. Por otra vía a la inicialmente prevista por el Ejecutivo, pero se ha conseguido. Asimismo, el hecho de que no se reconozca legitimación activa a las personas físicas para la interposición de este recurso de casación ayuda a descargar de trabajo en esta materia al Tribunal Supremo ${ }^{21}$.

En definitiva, a pesar de las deficiencias técnicas que la reforma del recurso de casación llevada a cabo por el Real Decreto Ley 8/2021 presenta, ha conseguido parcialmente el objetivo perseguido de la homogeneidad en la respuesta judicial a las medidas restrictivas de derechos acordadas, esencialmente, por las comunidades autónomas desde bien temprano, acabando con las limitaciones genéricas y desproporcionadas, a juicio del Alto Tribunal, en la limitación de algunos derechos fundamentales, como el de la libertad de circulación de personas o el de reunión, por los que algunas de ellas habían optado, aportando así seguridad jurídica al estado de caos en el que nos movimos en el período de medió entre los dos estados de alarma nacionales decretados por el Gobierno y evitando el colapso que presagiaba el vaticinio formulado por el propio gabinete técnico del Tribunal Supremo. Por consiguiente, adelantándonos al análisis que se abordará en el apartado siguiente, la reforma del recurso de casación llevada a cabo en mayo de 2021 era una deficiencia jurídica que se ha tornado en un éxito fáctico.

\section{ANÁLISIS DE LAS RESOLUCIONES JUDICIALES DICTADAS POR EL TRIBUNAL SUPREMO HASTA AHORA}

Como acabamos de apuntar, los presagios acerca de la avalancha de recursos que llegarían al Tribunal Supremo por la vía de esta reforma del recurso de casación no se han cumplido, de momento. El Tribunal Supremo ha sido muy claro en los pronunciamientos que, hasta hoy, ha tenido que emitir respecto a este tipo de cuestiones, consiguiendo así, de manera muy efectiva, el objetivo que se marcó el Ejecutivo cuando apostó por esta opción legislativa de reformar el recurso de casación, de tal forma que, de manera paradójica, lo que se articuló mal de iure por el Ejecutivo se está solucionando bien de facto gracias a la pericia argumentativa e interpretativa de las Sala Tercera. No obstante, no debemos lanzar las campanas al vuelo, ya que, como pudimos ver a lo largo de las semanas de la llamada quinta ola, un potencial empeoramiento de la situación epidemiológica

21 En su auto de 9 de junio de 2021 (ATS 7169/2021), el Tribunal Supremo deniega la legitimación activa a los particulares para la interposición de este recurso de casación. Indica el Alto Tribunal en su fundamento jurídico tercero que: «[...] esta Sala ya ha denegado la legitimación activa de las personas físicas para impugnar en casación la ratificación o autorización judicial de las Salas de los Tribunales Superiores de Justicia, de las medidas sanitarias acordadas por la Administración autonómica correspondiente, al no haber sido parte en la instancia». 
que obligue a las comunidades autónomas a adoptar nuevas medidas restrictivas de derechos fundamentales puede cambiar la situación de relativa calma en la que, al menos jurisprudencialmente, nos encontramos en estos momentos tras los dos pronunciamientos iniciales del Tribunal Supremo que ahora vamos a analizar.

Las dos resoluciones más relevantes hasta ahora son las de 24 de mayo y 3 de junio de 2021. En ellas, el Alto Tribunal ha renunciado expresamente al establecimiento de una jurisprudencia argumentando la variada y variable casuística de la materia y las diferentes situaciones que en el futuro se le pueden presentar, pero sí ha establecido unas líneas jurídicas claras y unos parámetros de control fiables.

La primera de las sentencias aludidas resuelve un recurso planteado por el Gobierno de Canarias contra el Auto del Tribunal Superior de Justicia de dicha comunidad de 9 de mayo en el que se rechazan las medidas de restricción impuestas por el Ejecutivo canario ${ }^{22}$. Y la segunda resuelve el recurso de casación plateado por el Ministerio Fiscal contra el Auto de 20 de mayo del Tribunal Superior de Justicia de las Islas Baleares por el que se ratifican las medidas limitativas de derechos adoptadas por el Gobierno de dicha comunidad autónoma tras la finalización del estado de alarma a nivel nacional el 9 de mayo de 2021.

Respecto de la primera sentencia, la de Canarias de 24 de mayo, el propio Tribunal Supremo quiso dar a conocer con cierta celeridad los puntos clave de su decisión por la relevancia que el asunto tenía para las posibles medidas limitativas que pudieran adoptar otras comunidades autónomas durante esos días.

Las cuestiones principales resueltas en dicha sentencia son las siguientes:

1. Que el art. 3 de la Ley Orgánica 3/1986 ha de interpretarse de manera conjunta con los arts. 26 de la Ley 14/1986 y 54 de la Ley 33/2011 y, así entendido, dichos preceptos otorgan una habilitación legal para establecer limitaciones puntuales de la libertad de circulación siempre que concurran los siguientes requisitos:

a. Que la Administración acredite la existencia de una enfermedad transmisible grave que ponga en peligro la salud y la vida de las personas.

b. Que se justifique que la limitación es imprescindible para impedir la transmisión por no haber otros medios menos intrusivos en la libertad de las personas y más eficaces para lograrlo

22 Véase también la sentencia del Tribunal Supremo de 27 de julio de 2021 por la que se resuelve el recurso de casación interpuesto por el Gobierno de Canarias y confirma el Auto del TSJ de dicha comunidad de 14 de julio por el que se rechazan las medidas de restricción adoptadas por el Gobierno de Canarias con fecha 8 de julio. En dicha sentencia, el Tribunal Supremo indica que tales medidas, entre las que se incluía un toque de queda para las islas en nivel de alarma sanitaria 4, son desproporcionadas y carentes de motivación. 
c. Que las medidas limitativas se determinen en función del número de enfermos y de su localización. Es decir, que se precise de manera clara la extensión subjetiva y territorial de la limitación.

d. Que se fije fundadamente el tiempo indispensable en que ha de mantenerse la limitación para impedir la difusión de la enfermedad.

2. Que el control judicial efectuado en el procedimiento de ratificación ha de consistir en la comprobación de que la Administración que pide la ratificación es la competente para adoptar las medidas a ratificar y ha cumplido lo siguiente:

a. Invoca los anteriores preceptos legales (art. 3 de la Ley Orgánica 3/1986, que ha de interpretarse de manera conjunta con los arts. 26 de la Ley 14/1986 y 54 de la Ley 33/2011) u otros que le confieran habilitación.

b. Identifica con suficiente claridad el peligro grave para la salud pública derivado de una enfermedad transmisible que es preciso conjurar para preservar el derecho a la salud y a la vida con indicación de los hechos que así lo acreditan

c. Establece debidamente la extensión de ese riesgo desde el punto de vista subjetivo, espacial y temporal.

d. Justifica que no dispone de otros medios menos agresivos para afrontarlo y que los propuestos son idóneos y proporcionados a tal fin.

Sobre esos presupuestos, la Sala debe juzgar si dicha justificación es suficiente y si la limitación pretendida es efectivamente idónea, necesaria y proporcionada.

Asimismo, ante la alegación que efectuaba el recurrente (Gobierno de Canarias) indicando que las mismas medidas que él había adoptado y el Tribunal Superior de Justicia de Canarias había rechazado eran las que otros tribunales superiores de justicia habían autorizado respecto a otros territorios autonómicos, el Tribunal Supremo indica que el Auto de rechazo de las medidas dictado por el Tribunal Superior de Justicia de Canarias no es contradictorio con el realizado por otras Salas territoriales porque no consta que las circunstancias contempladas por ellas sean las mismas que las de las Islas Canarias. Por último, el Alto Tribunal afirma que la resolución impugnada se ajusta a los parámetros señalados en los apartados anteriores, pues ha comprobado razonadamente la insuficiencia de la motivación ofrecida para justificar la limitación y la inconsistencia de las medidas con las excepciones previstas.

En relación con la Sentencia de 3 de junio de 2021 (recurso de casación del Ministerio Fiscal contra el auto del Tribunal Superior de Justicia de Baleares que autorizaba las medidas limitativas impuestas en dicha comunidad autónoma por el Gobierno de Baleares, la cuestión se centra, una vez identificada la cuestión de interés casacional objetivo por parte del Alto Tribunal, en la ratificación judicial del llamado "toque de queda" nocturno y del número máximo de personas 
en reuniones familiares y sociales, dejando fuera del objeto del recurso las otras medidas. El Ministerio Fiscal aduce que tanto una como otra medida inciden en la libertad de circulación y en el derecho a la intimidad familiar, proclamados respectivamente por los arts. 19 y 18 de la Constitución y observa que, si para establecer limitaciones semejantes se consideró necesario aprobar el estado de alarma, no cabe una vez finalizado este prolongarlas o reiterarlas. En otras palabras, entiende que el «derecho ordinario» de que habla la Sala de instancia, incluido el art. 3 de la Ley Orgánica 3/1986, no proporcionan la cobertura normativa constitucionalmente exigible para imponer el «toque de queda» nocturno o un número máximo de personas en reuniones familiares y sociales.

Además de este reproche de falta de suficiente cobertura o fundamento normativo, afirma el Ministerio Fiscal, en idéntico sentido al expresado en su voto particular por las magistradas del Tribunal Superior de Justicia de Baleares discrepantes con el auto del que trae causa este recurso de casación, que las medidas impuestas no superan el juicio de proporcionalidad a la vista de la situación epidemiológica. Por último, el Ministerio Fiscal afirma en su recurso que la limitación de la movilidad nocturna habría podido lograrse por medios menos invasivos, tales como el adelanto de la hora de cierre de establecimientos no esenciales, y que el control de la observancia del número máximo de personas reunidas en domicilios particulares es prácticamente imposible, de manera que la medida resulta innecesaria.

Es en los fundamentos jurídicos sexto y séptimo de esta sentencia donde el Tribunal Supremo establece la doctrina esencial en esta materia. Los aspectos más relevantes de este pronunciamiento contenidos en los fundamentos jurídicos que se acaban de indicar son los siguientes:

1. Que las comunidades autónomas, como ya indicó en la sentencia de 24 de mayo de 2021 analizada, pueden adoptar medidas sanitarias que supongan una restricción o limitación de derechos fundamentales, aunque dicha sentencia no resolvió todos los posibles problemas atinentes a la restricción o limitación de derechos fundamentales por parte de las comunidades autónomas, porque lo que se debatía entonces era la limitación de viajes entre islas en la Comunidad Autónoma de Canarias.

2. Que debe rechazarse la afirmación efectuada por el letrado de la Comunidad Autónoma de Baleares, con un supuesto apoyo en la ya analizada sentencia de 24 de mayo de 2021, de que la Sala de instancia no debía ir más allá de un control de la competencia de la Administración actuante, la invocación de las normas habilitantes, la identificación del peligro y el ámbito de aplicación (subjetivo, espacial y temporal) de las medidas. El Tribunal Supremo afirma que, ciertamente, la sentencia aludida dice que esos extremos deben ser controlados a la hora de ejercer la función prevista en el art. 10.8 de la Ley Jurisdiccional. Pero esto lo dice en un determinado contexto, a saber: para dejar claro que la ratificación judicial de naturaleza preventiva con- 
templada en el mencionado precepto legal no excluye la posibilidad de que cualquier persona que ostente un interés legítimo pueda después impugnar las medidas sanitarias judicialmente ratificadas mediante el recurso contencioso-administrativo. En otras palabras, el control judicial preventivo no es un examen exhaustivo de la legalidad de la actuación, ni, por supuesto, cercena el derecho a la tutela judicial efectiva de cualquier persona afectada por las medidas ratificadas. Por ello, no conviene sacar esa importante indicación de la sentencia fuera del contexto en que se hizo; y ello porque puede conducir al equívoco de pensar, como sugiere el letrado de la comunidad autónoma, que la función prevista en el art. 10.8 de la Ley Jurisdiccional queda circunscrita a un control preventivo predominantemente, cuando no exclusivamente, de la legalidad externa o formal de las medidas sanitarias adoptadas. Dicha sentencia no dice que ese control preventivo no deba versar también sobre la justificación sustantiva y la proporcionalidad de las medidas sanitarias en relación con las circunstancias del caso concreto. Más bien dice lo contrario.

3. Que la restricción de derechos fundamentales en el marco de la lucha contra la pandemia de la COVID-19 no exige siempre y necesariamente la cobertura del estado de alarma. Que el Gobierno y el Congreso de los Diputados considerasen necesario, en marzo y en octubre de 2020, declarar el estado de alarma y que con base en el mismo se restringieran determinados derechos fundamentales no significa que, una vez levantado el estado de alarma, no exista ninguna base constitucionalmente idónea para adoptar medidas sanitarias de lucha contra la pandemia que restrinjan algunos derechos fundamentales.

4. Una vez aclarado que cabe la restricción o limitación de derechos fundamentales en la lucha contra la pandemia de la COVID-19 sin necesidad del estado de alarma, el Tribunal Supremo pasa a analizar la idoneidad de la vigente legislación sanitaria para dar cobertura o fundamento normativo a tales restricciones. A este respecto, el Tribunal Supremo recuerda algo que ya dejó claro en la sentencia de 24 de mayo: que la restricción o limitación de derechos fundamentales no requiere ineluctablemente de cobertura mediante ley orgánica porque, de acuerdo con la doctrina del Tribunal Constitucional, ello solo es necesario cuando tal restricción implica desarrollo del derecho fundamental de que se trate; y desarrollo, a efectos del art. 81 de la Constitución, es tanto una regulación de conjunto del derecho fundamental como cualquier otra regulación que incida en elementos básicos, nucleares o consustanciales del mismo. Por ello, la reserva de ley orgánica para las medidas sanitarias que supongan restricción o limitación de algún derecho fundamental solo opera cuando tales medidas afecten a algún elemento básico, nuclear o consustancial. Y ello solo puede verificarse examinando cada norma que prevea la restricción de un derecho fundamental; nunca de antemano según un criterio 
estandarizado, pretendidamente válido para cualquier derecho, cualquier restricción y cualquier situación.

5. Según el Alto Tribunal, las restricciones de derechos fundamentales consideradas en este recurso de casación son bastante distintas de las que dieron lugar a la sentencia 719/2021 de 24 de mayo. Entonces se trataba de la limitación de los viajes entre islas, mientras que ahora se trata del «toque de queda» entre las 24 y las 6 horas para toda la población de la correspondiente comunidad autónoma y de un número máximo de personas en las reuniones familiares y sociales. Así, los derechos fundamentales no son exactamente los mismos: allí era únicamente la libertad de circulación en el territorio nacional (art. 19 de la Constitución), mientras que aquí están en juego también los derechos a la intimidad familiar y, aunque el Ministerio Fiscal no lo mencione en su recurso, el derecho de reunión (arts. 18 y 21 de la Constitución). Además, por lo que hace específicamente al llamado "toque de queda", probablemente está en juego algo más que la libertad de circulación, pues no es lo mismo prohibir desplazarse entre dos lugares determinados que obligar a todos a permanecer en su domicilio durante ciertas horas: esto último impide desplazarse a cualquier parte. Con todo ello quiere ponerse de relieve que la intensidad (la fuerza con que se incide en los derechos fundamentales) y la extensión (el número de personas afectadas en sus derechos fundamentales) no son equiparables en una limitación de viajes entre islas con un «toque de queda», por no hablar del número máximo de personas en reuniones familiares y sociales: estas últimas restricciones son considerablemente más intensas y extensas. Ello, como se verá, tiene relevancia a la hora de determinar tanto la cobertura normativa requerida como la justificación sustantiva de las medidas sanitarias restrictivas de derechos fundamentales. Consecuentemente, el Tribunal Supremo entiende que las medidas sanitarias adoptadas por el Gobierno de las Islas Baleares, precisamente por su severidad y por afectar a toda la población autonómica, inciden restrictivamente en elementos básicos de la libertad de circulación y del derecho a la intimidad familiar, así como del derecho de reunión. Ello significa que requieren de una ley orgánica que les proporcione la cobertura constitucionalmente exigible.

6. En este sentido, el Tribunal Supremo afirma que el art. 3 de la Ley Orgánica 3/1986 es innegablemente escueto y genérico. Desde luego, no fue pensado para una calamidad de la magnitud de la pandemia de la COVID-19, sino para los brotes infecciosos aislados que surgen habitualmente. Como ya indicó el Alto Tribunal en la tantas veces citada sentencia de 24 de mayo de 2021, las dificultades jurídicas serían mucho menores, tanto para la Administración sanitaria como para las Salas de lo Contencioso-Administrativo, si existiera una regulación suficientemente articu- 
lada de las condiciones y límites en que cabe restringir o limitar derechos fundamentales en emergencias y catástrofes como la actual ${ }^{23}$.

7. No obstante, a pesar de su parquedad, contrariamente a lo que sostiene el Ministerio Fiscal, el Alto Tribunal no cree que su carácter escueto y genérico prive al art. 3 de la Ley Orgánica 3/1986 de idoneidad para dar cobertura a medidas restrictivas de derechos fundamentales tan intensas como las analizadas en este recurso de casación, especialmente si se interpreta en conexión con las Leyes 14/2006 y 33/2011. Por referirse solo al «toque de queda», sería poco cuestionable que para combatir un pequeño brote infeccioso localizado en un pueblo pudiera la Administración sanitaria obligar a los vecinos a confinarse en sus domicilios; y seguramente algo similar cabría decir de la limitación de reuniones. Para el Tribunal Supremo, el problema no es, así, la intensidad: el problema es, más bien, la extensión: en la lucha contra la pandemia de la COVID-19 se han adoptado medidas sanitarias que restringen severamente derechos fundamentales para el conjunto de la población local, autonómica o nacional. Y es precisamente en este punto donde el art. 3 de la Ley Orgánica 3/1986 suscita dudas como fundamento normativo o norma de cobertura.

Por todo ello, concluye el Tribunal Supremo en su fundamento jurídico octavo que la aplicación de estos criterios al caso que es objeto de ese recurso de casación conduce a rechazar el motivo del Ministerio Fiscal consistente en que las medidas sanitarias ratificadas por el auto impugnado solo podían tomarse al amparo del estado de alarma. Pero acoge el motivo relativo a que tales medidas no superan el juicio de proporcionalidad.

Con estos dos pronunciamientos, el Tribunal Supremo, como ya se ha indicado, ha sido capaz de establecer unas líneas claras que, aunque no sientan jurisprudencia, sí sirven como "manual de restricciones», clarificando el marco legal con el que deben operar las comunidades autónomas a la hora de establecer limitaciones a los derechos fundamentales en una lucha contra la pandemia en la que se encuentran solas ante la dejación de funciones que el Gobierno central lleva haciendo. Legalidad, proporcionalidad y motivación son los parámetros de control que tendrán que servir de base a los tribunales a la hora de autorizar o ratificar la intensidad y la extensión de las medidas limitativas de derechos fundamentales que, en su caso, tengan que enjuiciar.

Como bien indica el Alto Tribunal en esta última sentencia analizada de 3 de junio, en una advertencia muy directa, todo sería mucho más fácil si existiera una regulación suficientemente articulada de las condiciones y límites en que cabe restringir o limitar derechos fundamentales en emergencias y catástrofes como la actual. La interpelación por parte de todos los operadores jurídicos para que el

23 Obsérvese el «toque de atención», tal y como se ha venido comentando, que el Tribunal Supremo efectúa al Gobierno en dicha sentencia. 
Gobierno aprobase un marco jurídico mucho más fiable, estable y claro sobre este particular ha sido prácticamente unánime, pero no se sabe por qué no ha formado parte de la agenda política del Gobierno de la nación hasta el día de hoy.

\section{DISTINCIÓN ENTRE MEDIDAS RESTRICTIVAS: RESTRICCIÓN DE DERECHOS FUNDAMENTALES Y RESTO DE MEDIDAS RESTRICTIVAS}

Parece conveniente subrayar la diferencia entre la naturaleza de las medidas que para la lucha contra la pandemia han ido dictando a lo largo de estos meses las diferentes Administraciones públicas, en España y en el resto del mundo. En efecto, algunas de ellas, las que se acaban de analizar y han sido objeto del recurso de casación introducido de nuevo cuño por el legislador español en mayo de 2021, afectan a derechos fundamentales y, por ende, son más intensivas, porque se proyectan sobre la esfera más nuclear de las actividades cotidianas de las personas, como su movilidad o el derecho de reunión, en los términos que ya se ha visto, y son también más extensivas porque pueden afectar, como de hecho ha ocurrido, a la totalidad de la población. Sin embargo, hay otro tipo de medidas, como el adelanto del cierre de los locales de ocio, de la hostelería o de las tiendas en general que no afectan a derechos fundamentales, pero sí a otros derechos como la libertad de empresa, regulada en el art. 38 de la Constitución, o al derecho al trabajo, regulado en el art. 35 de nuestra Carta Magna. Estas medidas no son tan extensas porque van dirigidas directamente a colectivos muy concretos, aunque indirectamente también condicionan la actividad cotidiana del conjunto de la sociedad. No obstante, también son intensas precisamente para los colectivos directamente afectados.

Las medidas limitativas de este tipo adoptadas también han sido objeto de control judicial. De hecho, ha habido resoluciones judiciales que las han rechazado de manera cautelar o definitiva alegando periculum in mora, ausencia de proporcionalidad y falta de seguridad jurídica al no establecer el período exacto de duración de dichas limitaciones ${ }^{24}$. No obstante, ni la reforma operada en la Ley Jurisdiccional en septiembre de 2020 ni la llevada a cabo respecto del recurso de casación en mayo de 2021 contemplan dentro de los procedimientos especiales y sumarios que se regulan ex novo la impugnación de este tipo de medidas limi-

24 Véase el auto de 9 de febrero de 2021 del Tribunal Superior de Justicia del País Vasco en el que se adopta la medida cautelar de suspensión de la vigencia del inciso relativo a reglas de reapertura del apartado 9.1) del anexo del Decreto 44/2020, de 10 de diciembre, prorrogado por Decreto 4/2021, de 22 de enero, del lehendakari. En sentido inverso, véase el auto del Tribunal Superior de Justicia de Navarra de 27 de octubre de 2020, por el que se deniega la medida cautelar solicitada por la Asociación de Empresarios de Hostelería y Turismo de Navarra y la Asociación Navarra de Pequeńa Empresa de Hostelería. 
tativas, por lo que la impugnación de estas debe llevarse a cabo a través del procedimiento ordinario contemplado en la citada Ley 29/1998 al no estar derechos fundamentales en juego. Tanto la reforma de la Ley de la Jurisdicción Contencioso-Administrativa de septiembre de 2020 como la de mayo de 2021 se centran en las medidas limitativas que afectan a derechos fundamentales, pero dejan fuera estas otras medidas limitativas de derechos que no están recogidos como fundamentales en la Constitución de 1978. Cabe plantearse en este segundo supuesto, el de la reforma de mayo de 2021, si existe un verdadero interés casacional en la adopción de este tipo de medidas limitativas de derechos, a pesar de que el nuevo supuesto casacional nada dice respecto de este tipo de medidas limitativas que no afectan a derechos fundamentales. Hasta la fecha no se ha planteado en la práctica ningún recurso de casación por esta vía, pero, en caso de hacerlo, desde nuestro punto de vista el interés casacional en la materia es evidente por las mismas razones por las que el propio Tribunal Supremo ha justificado el interés casacional de las medidas limitativas de derechos fundamentales: porque afectan a un amplio espectro de población (extensión de las medidas), máxime en Espańa, donde los establecimientos de hostelería se cuentan por cientos de miles, porque son medidas muy intrusivas en derechos no fundamentales pero sí esenciales (intensidad de las medidas), y porque también aquí es necesario establecer una jurisprudencia homogénea al respecto que aporte seguridad jurídica a las comunidades autónomas, que son la Administración pública territorial que ha venido adoptándolas. Y dicho interés casacional podría ser atendido por la interposición ordinaria de tal recurso ante el Tribunal Supremo.

Por consiguiente, dichas medidas son fiscalizables en sede jurisdiccional, pero de forma diferente a cómo se fiscalizan las medidas limitativas de derechos fundamentales. En este caso, se deben impugnar por el procedimiento ordinario, pudiendo solicitar la medida cautelar de suspensión de estas, como de hecho han venido haciendo las diferentes Asociaciones de Hostelería de las distintas partes del territorio nacional. El otorgamiento o la denegación de dicha medida cautelar se hará por parte de los tribunales ponderando los intereses en juego, como es el supuesto tradicional, es decir, cómo sufre el interés público en caso de otorgarse la medida cautelar solicitada y como sufre el interés del recurrente en caso de que no se otorgue. El parámetro que han tenido en cuenta los distintos tribunales superiores de justicia para adoptar o no la medida cautelar de suspensión de esas limitaciones ha sido similar a uno de los que ya hemos analizado en el caso de la adopción de medidas limitativas de derechos fundamentales: el criterio de la proporcionalidad, al que se ha sumado, en este caso, el criterio de la seguridad jurídica, exigiendo que se concretase el período de duración de dichas medidas. Pero, sobre todo, se ha tenido en cuenta la evolución del estado epidemiológico de cada ámbito territorial en el momento en que le han llegado este tipo de recursos a los diferentes tribunales superiores de justicia.

No entraremos aquí, por no ser objeto específico de este trabajo, en si tales medidas limitativas de derechos no fundamentales, pero que afectan a la libertad 
de empresa y al derecho al trabajo, pueden conllevar responsabilidades para las Administraciones públicas que las han adoptado. Es un interesante debate que debemos dejar simplemente expuesto y que el Tribunal Constitucional, en un exceso de jurisdicción, desde mi punto de vista, se ha encargado de condicionar en su reciente sentencia de 14 de julio de 2021 sobre el primer estado de alarma de ámbito nacional al indicar que existía el deber jurídico de soportar todas las limitaciones que bajo la vigencia de este se impusieron. Es, desde luego, una afirmación un tanto sorprendente si se tiene en cuenta que en ese mismo pronunciamiento el tribunal está aceptando la antijuridicidad del estado de alarma, lo que, unido al hecho de que algunas de estas medidas limitativas que se han adoptado, bajo la vigencia de aquel y sin la vigencia del mismo, han ocasionado daños efectivos, evaluables económicamente e individualizados con respecto a una persona o un colectivo de personas perfectamente identificadas e identificables hace que surja el debate acerca de si se han cumplido o no todos los requisitos exigidos por nuestro ordenamiento jurídico en el art. 32 de la Ley 40/2015 para un reconocimiento de responsabilidad patrimonial de la Administración o si existía en verdad el deber jurídico de soportarlos, como afirma el Tribunal Constitucional $\mathrm{o}$, incluso, si han venido motivados por una fuerza mayor.

\section{EL CERTIFICADO COVID COMO MEDIDA LIMITATIVA DE LA MOVILIDAD SOCIAL. MÁS LEÑA AL FUEGO}

La aprobación por parte de las autoridades comunitarias europeas del Reglamento (UE) 2021/953 del Parlamento Europeo y del Consejo de 14 de junio de 2021 relativo a un marco para la expedición, verificación y aceptación de certificados COVID-19 interoperables de vacunación, de prueba diagnóstica y de recuperación (certificado COVID digital de la UE) ha supuesto la introducción de un nuevo elemento polémico de limitación de un derecho fundamental consagrado a nivel de los tratados, como es la libre circulación de personas en el ámbito de la Unión. Este reglamento entró en vigor el 15 de junio de 2021 y es directamente aplicable a partir del 1 de julio de 2021 hasta el 30 de junio de 2022. Tanto su tramitación como su aplicación práctica han estado presididas por las dudas que desde el punto de vista jurídico, ético y social plantea este nuevo instrumento de control sobre los movimientos de los ciudadanos europeos.

Este certificado se expide por los Estados miembros de la Unión de forma homogénea e interoperativa y tiene como objetivo poder controlar la entrada de ciudadanos de otros países miembros por razones de salud, lo cual ya había sido previsto en normas anteriores como excepción a la libre circulación de personas en el territorio Schengen. El principal problema que plantea esta restricción de movimientos es la discriminación que conlleva, pues podrán moverse libremente por el territorio de los Estados miembros de la Unión todos los que se hayan vacunado, que presenten una prueba diagnóstica negativa o que puedan demos- 
trar que han pasado la COVID-19 y se han recuperado, no pudiendo entrar en dichos Estados aquellos otros ciudadanos que no puedan acreditar alguno de los tres requisitos anteriores. El hecho de que no toda la población haya podido acceder todavía a la vacuna puede suponer que la discriminación de los ciudadanos no vacunados sea injusta. Se dirá que pueden cumplir con otros requisitos, como es la presentación de una prueba diagnóstica negativa, pero ello también supone un coste adicional que, en muchos casos, no puede ser asumido por todos los ciudadanos. En realidad, desde el punto de vista jurídico, lo que debemos analizar, como en el caso del resto de medidas limitativas de derechos que se están adoptando para afrontar esta pandemia, es si dicho certificado tiene encaje legal y hasta constitucional, diría yo, y si es una medida proporcionada o no.

El encaje legal se ha llevado a cabo mediante la aprobación del citado Reglamento 2021/953. No obstante, esta medida choca frontalmente con el art. 3, apdo. 2, del Tratado de la Unión Europea, art. 21 del Tratado de Funcionamiento de la Unión Europea (TFUE); títulos IV y V del TFUE, y art. 45 de la Carta de los Derechos Fundamentales de la Unión Europea. Asimismo, a nivel nacional español, entraría en colisión con lo establecido en el art. 19 de nuestra Constitución. Sin embargo, como ya se ha apuntado anteriormente, tanto la legislación comunitaria como la legislación sectorial sanitaria interna española regulan supuestos en los que, por motivos de orden público o sanitarios, se pueden establecer excepciones a la libertad de movimientos, por lo que la base legal para el establecimiento de este tipo de medidas parece cumplirse.

En cuanto a la proporcionalidad, los Estados miembros de la Unión y los Estados no miembros de la Unión Europea han estado aplicando de manera sistemáticamente durante esta pandemia el principio de precaución o de cautela. En este sentido, en función de la situación epidemiológica que se ha ido dando en sus respectivos ámbitos territoriales, han ido relajando o endureciendo tanto los requisitos de entrada como de salida de sus ciudadanos, lo cual parece también razonable y proporcional si tenemos en cuenta los parámetros de control de medidas restrictivas de derechos que nuestra jurisprudencia ha ido exigiendo y que ya han sido analizadas en los apartados anteriores.

Sin embargo, el problema jurídico adicional que se plantea ahora es la extensión de este tipo de medidas restrictivas de la movilidad de los ciudadanos a otros ámbitos o actividades, no solo a la de los viajes. El certificado COVID europeo está pensado primordialmente para controlar los desplazamientos de los ciudadanos entre los Estados miembros de la Unión. Pero desde el mes de julio de 2021 estas restricciones de movilidad se están ampliando por parte de algunos Estados a otros ámbitos, como el ocio o el transporte público. Es decir, a todas aquellas actividades cotidianas que supongan interacción o relación social.

Si volvemos a utilizar los parámetros de control aludidos (legalidad y proporcionalidad), nos encontramos con que países como Grecia, Francia o Italia ya han aprobado una normativa ad hoc para regular este tipo de limitaciones y que, por tanto, su aplicación tenga una cobertura legal. No obstante, desde el punto 
de vista de la proporcionalidad no parece que una medida tan intrusiva e invasiva como de la que estamos hablando sea proporcionada, pudiendo existir alternativas menos agresivas para mitigar los efectos de la pandemia. Entrar a regular el acceso de los ciudadanos de manera discriminatoria a actividades cotidianas como estas plantea problemas éticos de primer orden. Piénsese, por ejemplo, en el choque frontal que estas medidas tienen, por ejemplo, con el principio de acceso universal a los servicios públicos, como es el transporte. Por no hablar de la efectividad de dichas medidas, pues autorizar que un número muy considerable de actividades cotidianas solo pueda ser llevada a cabo por personas vacunadas no asegura el control de la pandemia, puesto que las personas vacunadas también pueden contagiarse y contagiar. Como se ponía de manifiesto anteriormente, el hecho de que no toda la población haya tenido la oportunidad de vacunarse añade otro ingrediente agrio a la aplicación de este tipo de medidas, cuya extensión progresiva puede crear una nueva categoría de ciudadanos de segunda división que podría fomentar si se extiende en el tiempo hasta una nueva brecha social. Adicionalmente, la aplicación práctica de estas medidas tiene una transcendencia notable desde el punto de vista de la protección de datos, pues supone ir dejando «rastro» de los datos sanitarios de un contingente importante de ciudadanos ${ }^{25}$, los vacunados, en manos de sujetos privados que no se sabe a ciencia cierta si van a hacer un buen o mal uso de esos datos ${ }^{26}$. Si este tipo de restricciones de acceso a diferentes actividades sigue extendiéndose, ¿̨hasta dónde va a llegar?

25 La sentencia del Tribunal Supremo de 14 de septiembre de 2021, en su fundamento jurídico octavo, no aprecia que la exigencia del pasaporte COVID para entrar en establecimientos de ocio o de hostelería vulnere el derecho fundamental a la protección de datos, afirmando literalmente en uno de los apartados de dicho fundamento jurídico que «no se aprecia limitación alguna, cuando lo que se establece, para entrar en el interior de un determinado establecimiento, es la mera exhibición, es decir, enseñar o mostrar la documentación en cualquiera de las tres modalidades exigida». Hay que explicar que dicha afirmación se efectúa dentro del contexto de la ratificación de las medidas aprobadas por Orden, de 13 de agosto de 2021, del consejero de Sanidad de la citada Xunta, rechazadas inicialmente por el Tribunal Superior de Justicia de dicha comunidad autónoma. La citada orden prohibía la conservación de los datos o la creación de ficheros por parte de los establecimientos a los que se les exige la comprobación de que el asistente está en posesión del citado pasaporte COVID. El Tribunal Supremo lo expresa de manera bastante rotunda en el párrafo siguiente al que se acaba de citar literalmente. Dice así: «Sin que, desde luego, puedan recogerse los datos de los asistentes a tales locales, ni pueda elaborarse un fichero, ni hacer un tratamiento informático al respecto. Pues nada de esto se permite en la citada Orden que impone la medida. Al contrario, en la misma se advierte que se trata de «la exhibición» de dichos certificados en «el momento de acceso» al local, y expresamente establece una prohibición, pues «no se conservarán esos datos ni se crearán ficheros con ellos». De modo que no concurre limitación alguna de este derecho fundamental».

26 Sobre la protección de datos en tiempos de COVID, véase J. L Piñar Mańas (2020), «Transparencia y protección de datos en el estado de alarma y en la sociedad digital post COVID-19", págs. 135 a 184, en D. Blanquer Criado (2020: 15). 
De momento, en España el Gobierno central no ha expresado su intención de aplicar estas medidas restrictivas de movilidad a ese tipo de actividades. Pero ya hay comunidades autónomas que están empezando a exigir requisitos de entrada en establecimientos de hostelería, lo que, de nuevo, plantea dudas jurídicas más que razonables acerca de que las comunidades autónomas, por su cuenta y riesgo, puedan limitar un derecho fundamental como este. El parámetro de la legalidad puede ser superado si se hace una interpretación extensiva y peligrosa de los arts. 3 de la Ley Orgánica 3/1986, de 14 de abril, de medidas especiales en materia de Sanidad, del art. 24 de la Ley 14/1986, de 25 de abril, General de Sanidad o 56 de la Ley 33/2011, de 4 de octubre, General de Salud Pública, tal y como ha exigido nuestro Tribunal Supremo en la sentencia ya analizada de 3 de junio de 2021. Sin embargo, desde mi punto de vista, es dudoso que pudiera superar el parámetro de la proporcionalidad. Existen medidas menos agresivas e intrusivas para conseguir controlar la pandemia. El reinado de la interpretación extensiva del principio de precaución y cautela que está caracterizando esta pandemia no puede desconocer la existencia de otros principios de suma importancia en el derecho público, como, por ejemplo, el principio de favor libertatis.

Afortunadamente, de nuevo, nuestra jurisprudencia ha reaccionado con sensatez y no ha autorizado dichas medidas. El Tribunal Supremo ha extendiendo a este ámbito de restricciones los parámetros de control utilizados en su ya citada sentencia de 3 de junio de 2021 y ha confirmado las sentencias de los tribunales superiores de justicia que no han ratificado los intentos de algunas comunidades autónomas por imponer el pasaporte COVID para el acceso a los locales de hostelería. Proporcionalidad, justificación e idoneidad, delimitación espacial y temporal clara en función de los indicadores de la pandemia y búsqueda de medidas alternativas menos restrictivas y más eficaces son los criterios empleados, también aquí, de manera sensata, por nuestra jurisprudencia para fiscalizar y autorizar medidas tan quirúrgicas y desatinadas como las que se intentan imponer de manera indiscriminada para toda la ciudadanía por parte de algunas Administraciones públicas ${ }^{27}$.

27 Véase la sentencia del Tribunal Supremo de 18 de agosto de 2021 por la que se resuelve el recurso de casación interpuesto por la Junta de Andalucía contra el auto del TSJ de Andalucía (Sala de Granada) de 6 de agosto de 2021, confirmando dicho auto que no ratificó las medidas restrictivas de derechos contenidas en la Orden de 5 de agosto de 2021 de la Consejería de Salud y Familias, consistente en «limitar el acceso al interior de los establecimientos de esparcimiento y de hostelería con música definidos de conformidad con lo establecido respectivamente en los epígrafes III.2.8.a) y III.2.7, del Decreto 155/2018, de 31 de julio, a aquéllas personas que puedan acreditar estar en posesión de Certificado COVID Digital de la UE en vigor o acreditación de PDIA (test antígeno o PCR negativa) en las últimas 72 horas realizada en centros, servicios o establecimientos sanitarios».

En idéntico sentido, siguiendo la reciente, pero ya aquilatada doctrina del Tribunal Supremo, se han pronunciado los TSJ de Galicia y de Canarias, considerando desproporcionada e ineficaz esta medida. 
Es de agradecer que el Tribunal Supremo haya establecido desde el principio de sus actuaciones, tras la reforma del recurso de casación de mayo de 2021 que aquí se está comentando, unos criterios claros que están siendo seguidos por los tribunales superiores de justicia y que han aportado luz jurisprudencial a la oscuridad legislativa, mejorando notablemente la seguridad jurídica del marco de actuación de las medidas restrictivas de derechos fundamentales que las Administraciones públicas pueden adoptar en su lucha contra la pandemia.

\section{DE NUEVO EN LA LUCHA CONTRA LAS INMUNIDADES DEL PODER}

La pandemia de la COVID-19 ha puesto, de nuevo, de máxima actualidad el famoso y veterano artículo del profesor García de Enterría sobre la lucha contra las inmunidades del poder ${ }^{28}$ escrito sobre la base de la conferencia inaugural del curso académico de 1962 en la Universidad de Barcelona.

Sin embargo, la ya citada sentencia del Tribunal Supremo de 14 de septiembre de 2021 (nota 25) autoriza el pasaporte COVID en Galicia, lo que parecería una contradicción jurisprudencial. Pero no lo es. Todo lo contrario. Es un pronunciamiento coherente con la línea argumental y los parámetros de control expresados en este trabajo y llevados a cabo por el Tribunal Supremo desde las tantas veces mencionadas sentencias de 24 de mayo y de 3 de junio de 2021, puesto que en septiembre el Alto Tribunal autoriza a Galicia lo que en agosto le denegó. Pero el que cambia no es el Tribunal Supremo, sino que la que cambia es la Xunta de Galicia, que presenta ante los tribunales una orden muy diferente a la que los tribunales rechazaron en agosto. ¿En qué consisten esos cambios? Muy sencillo: en exigir el pasaporte COVID solo en aquellas zonas con alta incidencia pandémica en vez de exigirlo de forma generalizada para toda la Comunidad Autónoma de Galicia, como se contenía en la orden rechazada por el Tribunal Supremo en agosto. Es decir, el Tribunal Supremo aplica a la exigencia de pasaporte COVID para el acceso a establecimientos de ocio o de hostelería (y en el futuro, en función de la evolución de la pandemia, podría plantearse para el acceso a otros servicios públicos, como pudiera ser el transporte) los mismos criterios que ha utilizado para autorizar o rechazar el resto de medidas de limitación de los derechos fundamentales. Entre otras cosas porque, como bien indica en este pronunciamiento de 14 de septiembre de 2021, está en juego el mismo derecho fundamental: el derecho de circulación de las personas del art. 19 de la Constitución. Por tanto, en agosto se rechaza la orden de la Consejería de Sanidad de la Xunta por exigir el pasaporte COVID de manera generalizada en toda la Comunidad Autónoma de Galicia, lo que es desproporcionado e injustificado. En septiembre se autoriza porque la nueva orden aprobada por la Xunta solo lo exige de manera quirúrgica y limitada en aquellos ámbitos territoriales donde el índice de incidencia de la pandemia sea muy alto. De nuevo vemos cómo el problema no es la intensidad de la limitación, sino la extensión desproporcionada e injustificada de la misma.

28 E. García de Enterría (1962), «La lucha contra las inmunidades del poder en el Derecho administrativo (poderes discrecionales, poderes de gobierno, poderes normativos)", Revista 
La pléyade de medidas intensivas e intrusivas adoptadas por las Administraciones públicas territoriales a lo largo de estos meses hace más necesario que nunca el control judicial de las mismas, tanto a nivel constitucional como de legalidad ordinaria. Ambos controles se han ejercido por parte de los tribunales de nuestro país. Y la radiografía que ha quedado no ha sido precisamente idílica por lo que a los instrumentos jurídicos utilizados por parte del poder ejecutivo hace referencia. Tanto la reciente sentencia del Tribunal Constitucional de 14 de julio de 2021 que resuelve el recurso de inconstitucionalidad planteado por el partido político VOX como los pronunciamientos y advertencias que los tribunales han realizado al Gobierno de la nación y a las comunidades autónomas sobre las medidas adoptadas en la lucha contra la pandemia ponen de manifiesto que los derechos de los ciudadanos han sido sistemáticamente pisoteado ${ }^{29}$. Y se ha hecho de la peor manera posible; no respetando los dos pilares esenciales del Estado de derecho: el principio de legalidad y la separación de poderes ${ }^{30}$.

Por lo que hace referencia al principio de legalidad, el que se haya utilizado de manera tan intensa el estado de alarma para suspender derechos cuando el instrumento jurídico adecuado para que dicha suspensión fuese conforme a derecho era el estado de excepción es un hecho de una gravedad poco común que conculca la legalidad constitucional, como ya ha quedado dicho por el Tribunal Constitucional, quien también se ha pronunciado ya de manera negativa sobre la validez del segundo estado de alarma, prolongado nada más y nada menos que seis meses, lo que tiene difícil encaje con la regulación que de dicho instrumento jurídico efectúa nuestra Constitución y con el espíritu de provisionalidad que el citado texto quiere dar a todos y cada uno de los tres estados de excepcionalidad regulados en su art. 116. Pero con ser esto grave, no es lo único. Las numerosas resoluciones judiciales que han anulado algunas de las decisiones que durante la vigencia de los estados de alarma de nivel nacional se han aprobado confirman la impresión de que el principio de legalidad ha sido seriamente atacado en nuestro país, tanto por el Gobierno de la nación como por el resto de los gobiernos territoriales ${ }^{31}$.

de Administración Pública, 38, págs. 159-205. O el libro del mismo autor, (2016), La lucha contra las inmunidades del poder, Madrid: Editorial Civitas, $3^{\text {a }}$ edición.

Sobre la distinción entre suspensión y limitación de derechos fundamentales y el control judicial de las restricciones de derechos fundamentales en relación con la reciente y citada sentencia del Tribunal Constitucional de 14 de julio de 2021, véase F. Velasco Caballero (2020), "Libertades públicas durante el estado de alarma por la COVID-19», págs. 79128, en D. Blanquer Criado (2020: 15).

30 El preámbulo del profesor T. R. Fernández Rodríguez en el libro colectivo coordinado por D. Blanquer Criado es sintomático de lo que se comenta: «El Estado de Derecho a prueba», págs. 19-25, en D. Blanquer Criado (2020: 15).

31 Sobre la manipulación del sistema de fuentes y demás deficiencias jurídicas cometidas durante la vigencia, sobre todo, del primer estado de alarma, véase M. M. Fernando Pablo (2021: 8). 
Respecto a los ataques y desprecios a la división de poderes, está directamente relacionado con lo que se acaba de comentar. La explicación a un primer estado de alarma excesivo en la suspensión de derechos que no se articuló por la vía del estado de excepción y de un segundo estado de alarma prolongado en el tiempo con esa prórroga de seis meses se encuentra en el hecho de que el Ejecutivo no quería someterse al control parlamentario en las decisiones que iba tomando durante la vigencia de dichos estados de alarma. El papel del Parlamento, como ya se ha puesto de manifiesto en otro apartado de este trabajo y se ha encargado de confirmar el Tribunal Constitucional en su reciente sentencia de 5 de octubre de 2021, ha sido absolutamente residual cuando debería haber sido esencial.

Pero, de nuevo, si ello no fuera suficientemente grave, la posición jurídica en que se ha situado el poder judicial a la hora de tener que ratificar o autorizar medidas tan intrusivas en los derechos de los ciudadanos es más que discutible, como también hemos tenido ocasión de comentar aquí. Las competencias de autorización y ratificación de unas medidas administrativas que todavía no están en vigor no es el papel que la jurisdicción contencioso-administrativa debe jugar. Su papel es controlar actos o actuaciones ya firmes y no proyectos de actuación de las Administraciones públicas territoriales, tal y como indican los arts. 117 de la Constitución y los arts. 1.1 y 25 de la Ley 29/1998. Ya veremos qué dice el Tribunal Constitucional respecto a la cuestión de constitucionalidad planteada en tal sentido por el Tribunal Superior de Justicia de Aragón, pero los argumentos esgrimidos por este último órgano jurisdiccional en la citada cuestión planteada son bastante sensatos. La decisión gubernamental de no aprobar una ley específica que otorgase un marco de seguridad jurídica a las decisiones que para la lucha contra la pandemia pareciera dar la impresión de que esté motivada en un intento de no asumir el coste político que tales decisiones restrictivas tienen. Así, el Gobierno ha preferido trasladar al poder judicial una función de dudosa constitucionalidad y que sea este poder del Estado el que tenga que lidiar con las consecuencias que de ello se deriven.

La lucha contra las inmunidades del poder está más vigente que nunca en nuestro país y está funcionando razonablemente bien gracias al camino bien asfaltado que la doctrina administrativista española de la generación de la RAP fue construyendo desde los ańos cincuenta del siglo pasado ${ }^{32}$. Prueba de ello son las resoluciones judiciales, tanto por la vía de la adopción de medidas cautelares como por la de sentencias ejemplares en la forma y en el fondo, que han conse-

En idéntico sentido, véase J. A. Santamaría Pastor (2020), «Sobre el ejercicio de las potestades normativas en tiempos de pandemia», págs. 207-240, en D. Blanquer Criado (2020: 15).

32 Téngase en cuenta el capítulo de A. Arévalo Gutiérrez (2021), «Decretos y Decretos leyes: el control de las medidas adoptadas durante la crisis», págs. 31-45, en A. J. Alonso Timón (2021: 13). 
guido rectificar decisiones administrativas arbitrarias que rayaban en un despotismo iletrado desde el punto de vista jurídico ${ }^{33}$.

La batalla planteada por los diferentes poderes ejecutivos en general y el espańol en particular con la excusa de la pandemia está siendo cruenta, la más cruenta que se recuerda en los últimos años. Pero, de momento, el sistema de contrapesos está funcionando. Prueba de ello es que, a pesar de la prolongada duración del segundo estado de alarma a nivel nacional, durante su vigencia se corrigieron algunos de los excesos cometidos en la limitación de los derechos fundamentales de los ciudadanos durante la vigencia del primero.

Cuando se tensiona la democracia solo queda la ley y la división de poderes para poder garantizar el triunfo de la libertad. La libertad está hoy amenazada en casi todas las partes del mundo. Las democracias liberales corren un gran riesgo sistémico. Pero de peores situaciones han salido y en peores plazas han toreado. Esperemos que las democracias liberales salgan también victoriosas de esta crisis institucional que afecta a todo Occidente.

\section{CONCLUSIONES}

- La reforma de la Ley 29/1998, de 13 de julio, de la Jurisdicción Contencioso-Administrativa para introducir un recurso de casación para el control de las medidas de restricción de derechos fundamentales adoptadas por las Administraciones públicas territoriales para la lucha contra la pandemia de la COVID-19 adolece de defectos de técnica jurídica.

- El objetivo de la reforma introducida en mayo de 2021, que era la homogeneización de la respuesta jurisprudencial a estas medidas de restricción, no se ha conseguido totalmente porque el Tribunal Supremo, si bien es cierto que en sus primeras resoluciones ha establecido unos parámetros de control claros y ha proporcionado pistas más que razonables que mejoran la seguridad jurídica en esta materia, ha renunciado a sentar jurisprudencia, alegando que la casuística tan variada con la que se puede encontrar pro futuro impide la homogeneización de sus resoluciones, tal y como pretendía el Gobierno. No obstante, la labor del Tribunal Supremo llevada a cabo hasta ahora ha evitado la avalancha de recursos que inicialmente se presuponía y ha aportado luz a la oscuridad que se vivió durante el período intermedio entre los dos estados de alarma de nivel nacional.

- La situación en la que se ha situado a los tribunales a la hora de autorizar o ratificar medidas administrativas que ni siquiera han entrado en vigor es de

33 Sobre la producción normativa llevada a cabo durante la vigencia del derecho de excepción y su coexistencia temporal con el «Derecho de la normalidad», véase J. J. Lavilla Rubira (2021), «Posición ordinamental y régimen jurídico de las normas reglamentarias dictadas por las autoridades competentes delegadas», págs. 47-56, en A. J. Alonso Timón (2021: 13). 
dudosa constitucionalidad, puesto que, como ya ha tenido ocasión de pronunciarse algún órgano jurisdiccional, sitúa en una posición de colaborador necesario de la Administración a los tribunales, ejerciendo labores administrativas y no jurisdiccionales, y puede suponer un ataque a la división de poderes.

- Las comunidades autónomas, que no tenían claro lo que podían o no podían hacer en materia de restricciones sin el paraguas del estado de alarma, cuentan ahora con una mayor seguridad jurídica sobre las medidas restrictivas de derechos fundamentales que pueden adoptar después de los pronunciamientos del Tribunal Supremo de 24 de mayo y de 3 de junio de 2021. Las medidas restrictivas que adoptan ahora las comunidades autónomas son cada vez más respetuosas con los parámetros establecidos por el Tribunal Supremo en sus primeros pronunciamientos.

- Las comunidades autónomas pueden adoptar medidas restrictivas de derechos fundamentales siempre que respeten los límites de la legalidad, la proporcionalidad y la motivación. Así, pueden limitar el derecho de movilidad mediante el denominado «toque de queda» sin necesidad de que exista estado de alarma, pero siempre que esté justificado por la situación epidemiológica, sea proporcionado y esté motivado. Ese toque de queda tiene que estar delimitado y referido a ámbitos concretos en los que la situación epidemiológica lo justifique. No se pueden imponer toques de queda generalizados para toda la población, puesto que no se respetaría el parámetro de la proporcionalidad. No estamos, pues, ante un problema de intensidad de las medidas que pueden adoptar las comunidades autónomas sin el paraguas del estado de alarma, sino ante un problema de extensión generalizada de dichas medidas.

- Cobertura legal, competencia, proporcionalidad, justificación e idoneidad, delimitación espacial y temporal clara en función de los indicadores de la pandemia y búsqueda de medidas alternativas menos restrictivas son los criterios que, según el Tribunal Supremo, deben emplear los tribunales para ratificar o denegar las medidas restrictivas de derechos fundamentales que las Administraciones adopten en su lucha contra la pandemia.

- La extensión del certificado COVID como forma de restricción de la movilidad de las personas a otras actividades que no son las propias de los movimientos transfronterizos abre una espita peligrosa, desproporcionada, ineficaz y de difícil aplicación práctica que, afortunadamente, de momento, ha sido combatida de manera sensata por nuestra jurisprudencia.

- El principio de precaución como herramienta de lucha contra la pandemia debe conjugarse con el respeto a otros principios igualmente relevantes como, por ejemplo, el principio de favor libertatis. 
